\title{
The effect of light rail transit on land use in a city without zoning
}

\author{
Richard J. Lee \\ Washington State Department of Transportation \\ leerich@wsdot.wa.gov \\ Ipek N. Sener \\ Texas A\&M Transportation Institute \\ i-sener@tti.tamu.edu
}

\begin{abstract}
Light rail transit (LRT) has become a popular strategy to improve accessibility and mobility in the United States. It has also been touted as a tool to spur urban growth, higher-density development, and revitalization in large, auto-dependent cities like Houston, Texas. Although traditionally known as sprawling and highly autooriented, Houston has greatly expanded its light rail system in recent years. The city is also unique in that it is by far the largest city in the United States without zoning ordinances.

The city of Houston is used as a case study to examine land-use development around LRT stations. Analysis of parcel-level land-use data from 2005-2014 revealed a spike in commercial development along the original light rail corridor, approximately 4 to 10 years after its opening. Land-use development along the newer light rail corridors was more modest and not considerably different than the control corridors. Small changes in the levels of high-density residential housing and land-use mix near light rail stations indicated that efforts to encourage transit-oriented development have not yet had much effect.
\end{abstract}

Keywords: Light rail transit (LRT), land-use development, land-use mix, Houston, Texas

\section{Article history:}

Received: July 30, 2016

Received in revised form:

November 14, 2016

Accepted: January 25, 2017

Available online: March 9, 2017

\section{Introduction}

Light rail transit (LRT) has become an increasingly popular strategy to improve accessibility and manage congestion in US cities. It is commonly assumed that investment in LRT will help spur development and promote high-density mixed land uses. LRT may also stimulate growth by improving accessibility to once difficult to reach areas (Knowles \& Ferbrache, 2016). Cervero (1984) notes that growth potential is strongest when LRT is deployed in dense, economically robust, central areas. This notion is supported by several other studies indicating that land use impacts tend to occur in growing areas pre-

Copyright 2017 Richard J. Lee \& Ipek N. Sener

http://dx.doi.org/10.5198/jtlu.2017.926

ISSN: 1938-7849 | Licensed under the Creative Commons Attribution - Noncommercial License 3.0

The Journal of Transport and Land Use is the official journal of the World Society for Transport and Land Use (WSTLUR) and is published and sponsored by the University of Minnesota Center for Transportation Studies. 
disposed to high-density development (Handy, 2005), near the central business district (CBD) (Shen, 2013), and with available land and transit-oriented development (TOD)-supportive policies in place (Higgins, Ferguson, \& Kanaroglou, 2014). For example, Portland's east-side LRT line did not initially have the economic vitality or TOD-oriented planning necessary to support the desired high-density growth (Dueker \& Bianco, 1999). Similarly, Pacheco-Raguz (2010) did not find evidence for light rail stimulating land-use development in Manila, which the author partially attributes to a lack of policies supportive of TOD.

LRT is frequently associated with increased development near station areas, though it is often unclear whether LRT itself is responsible for the land-use change, or whether it simply tends to be situated in areas amenable to development. In some cases, rather than attracting new development, LRT may redistribute development toward station areas (Handy, 2005; Higgins et al., 2014). There was a substantial increase in development following the expansion of Denver's LRT system, with much of that growth focused in the revitalized downtown area (Ratner \& Goetz, 2013). The most central stations tended to have mixed-use, retail, and office developments, while outlying station areas were characterized by residential development. Fogarty and Austin (2011) also reported increased development around rail stations when analyzing recently opened LRT lines in Minneapolis, Denver, and Charlotte. The direct effects of LRT remained ambiguous as much of the growth may have been a consequence of proximity to employment centers and downtowns.

In Minneapolis, Hurst and West (2014) estimated land-use changes following the installation of the METRO Blue light rail line. Positive land-use change effects were found for parcels near LRT stations relative to the time of construction, but not when compared to the pre-construction period. Within-corridor analysis revealed that the primary beneficiaries of land-use growth were industrial and single-family parcels as opposed to vacant or commercial properties. Another study of LRT in Minneapolis found that proximity to the $\mathrm{CBD}$, mixed land use, and higher density were associated with a greater likelihood of land-use change (Hurst, 2011). Vacant and industrial properties were most likely to be developed, suggesting that variations in land-use changes are dependent upon existing land uses. An earlier analysis of land-use change around the Hiawatha line found no significant impact on land-use changes during the initial year of operation (Goetz, Ko, Hagar, Hoang, \& Matson, 2010), indicating that it may take several years for these effects to manifest.

The relationship between LRT and density is synergistic. LRT requires a certain level of density to thrive, while at the same time supporting and promoting higher-density development. An analysis of 11 LRT systems across the United States indicated that ridership is strongly associated with higher employment and residential densities (Cervero \& Zupan, 1996). More specifically, Cervero and Guerra (2011) estimated that LRT systems would benefit from residential densities of approximately 30 people per gross acre and a high concentration of jobs within a quarter-mile of stations. In reality, these densities are often difficult to achieve outside of downtowns as slower speeds (compared to heavy rail transit) make it more difficult to cultivate density (Shen, 2013). Many station areas may also face resistance to highdensity development from local residents. This "NIMBYism" is particularly prevalent for neighborhoods farther from CBDs with a large proportion of single-family housing (Porter, 1998; Shen, 2013). Another policy-related obstacle is that LRT station planning and routing is more frequently driven by cost considerations than growth potential (Cohen-Blankshtain \& Feitelson, 2011). For instance, rail lines are often situated along industrial corridors or less dense areas so as to take advantage of cheaper rights-of-way.

This study continues to explore these issues and aims to better understand land-use change in the city of Houston, Texas from 2005 to 2014 . Houston presents a fascinating case study for land-use change as it is well-known for its lack of zoning regulations. While there are regulatory measures in 
place that manage development in many of the same ways as zoning, there are fewer barriers to land-use change in Houston than there are in more strictly-zoned cities. The city is also large and sprawling with parking regulations, setback laws, and street widths that favor vehicular travel over pedestrian travel. Because its planning has been less TOD-oriented (i.e., higher density, mixed land use, and walkable neighborhoods) than some other cities with light rail, it presents an excellent opportunity to better isolate the effects of LRT on land use, separate from policy interventions.

\section{The case of Houston, Texas}

\subsection{Light rail transit in Houston}

Houston's first LRT line, the Red Line (hereafter referred to as the Original Red Line), began operation on January 1, 2004. The 7.5-mile line runs from just outside of the I-610 loop in the Medical Center neighborhood north to the University of Houston-Downtown in the CBD. Just before the opening of the Original Red Line, voters in Houston decided to expand LRT by approving funding for the Green (aka East End) Line, Purple (aka Southeast) Line, and a northern extension to the Red Line (hereafter referred to as the Red Line North). Construction on these lines began in 2008 and 2009. The Red Line North, which extended the Original Red Line through the Northside district, officially opened on December 21, 2013. The Green and Purple Lines followed in May 2015, introducing light rail service to the East End and Southeast Houston from the CBD. As of 2016, the Red Line (Original and North combined) had a daily weekday ridership of approximately 50,000, making it one of the busiest LRT lines in the country. Ridership for the newly-opened Green and Purple lines is currently just a fraction of the Red Line (Metropolitan Transit Authority of Harris County Texas, 2016).

Two other LRT lines have also been proposed for development, although at this point it is unclear when, or if, funding to build these lines will be secured. The proposed Blue (aka University) Line would head east from the Hillcroft Transit Center for approximately 10 miles to the University of Houston, roughly paralleling US-59/I-69. The proposed Gold (aka Uptown) Line would begin at the Northwest Transit Center and Head South through Uptown, serving Houston's high-end retail district and Post Oak Blvd. Given the current uncertainty over funding, the Gold Line is now being re-envisioned as a bus rapid transit line (Houston Chronicle, 2013) while federal funding for the Blue Line has been retracted due to a lack of progress (Begley, 2016).

\subsection{Land use in Houston}

Compared to other large American cities, Houston is well known for being large, sprawling, and lacking in density — conditions that have led to a high level of auto-dependence. Houston is also unique in that it is the largest city in the country without single-use zoning regulations. Instead, land-use planning in Houston follows a more laissez-faire approach with greater involvement from private groups such as developers, homeowners associations, and super neighborhood councils (Qian, 2010).

This is not to say that Houston does not have land-use policies. One way that the city has shaped land-use development is through the use of deed restrictions, which aim to restrict commercial development in residential areas and preserve neighborhood character. These essentially function much in the same way as single-use zoning (Lewyn, 2005), though as Qian (2010) points out, most expire after 30 years leaving neighborhoods with little legal recourse to oppose development. Other government planning initiatives include the creation of tax increment reinvestment zones (TIRZs) and the Land Assemblage Redevelopment Authority to aid in neighborhood redevelopment, and loosening minimum lot size restrictions within the I-610 ring to allow for more compact residential development in the center of 
the city (Qian, 2010). The city additionally adopted a buffering ordinance in 2011 that protects singlefamily residences from the development of neighboring high-rise buildings (City of Houston, 2011).

Houston has also made an effort to incorporate TOD planning practices along LRT corridors. In 2006, the city launched the Urban Corridor Planning initiative, which led to the passing of the Transit Corridor Ordinance (TCO) in 2009. With the goal of promoting walkability near rail, the TCO requires new developments along LRT corridors to maintain minimum sidewalk widths. Developers are also offered incentives to comply with optional pedestrian-friendly standards to further enhance walkability. In addition, Houston has received funding from the Houston-Galveston Area Council (HGAC) to plan multimodal livable centers in several areas of the city (City of Houston, n.d.). Much like TOD, this program emphasizes development that is walkable, mixed-use, and transit-friendly. Target neighborhoods for this program include the Original Red Line Ensemble/Houston Community College station area, the Upper Kirby neighborhood (which would be served by the proposed Blue Line), and the Red Line North neighborhoods. As Margerum, Brody, Parker, and McEwen (2013) noted, the integration of transit and multimodal accessibility are crucial elements in the development of urban centers.

In spite of these measures, there are very few examples of TOD in Houston. As of 2014, very few development projects had opted into the TCO (Hassell, Lewis, \& Auzenne, 2014; United States Government Accountability Office, 2014). Additionally, a 2014 case study of the recently-opened Red Line North found a predominance of low-density retail and residential land uses and very little evidence of TOD (United States Government Accountability Office, 2014). On the other hand, evidence of TOD around the Original Red Line is now starting to become apparent more than a decade after its opening. GreenStreet (formerly known as Houston Pavilions) is a three-block-long mixed retail and office space with pedestrian amenities and near the Main Street Square Station. It began development in 2004 soon after the introduction of LRT and opened in 2008, making it one of the first developments in Houston that could be considered a TOD, though the lack of residential units limits its efficacy in bringing travelers closer to rail. The development was annexed into the Main Street/Market Square TIRZ, but a review of the project notes that "hardly any evidence exists suggesting that the planning and design of the site was put in action as part of a wider plan for downtown" (Ozdil, Taylor, Li, Matttingly, \& Bell, 2011). Another recent development along the Original Red Line, Venue Museum District, opened in 2010. While not mixed-use, the six-story apartment building built atop a parking garage brought added density to the Museum District Station area.

More than any other neighborhood, the Midtown area has seen a surge in TOD in recent years with several mixed-use developments and upscale apartments currently being planned or under construction. Located next to the McGowen Original Red Line station, Midtown Park (scheduled to be completed in 2017) will transform a large parcel (approximately 25,000 $\mathrm{m}^{2}$ ) into a public park, retail stores, 300-unit apartment complex, and parking garage (Mulvaney, 2015). Just west of it, a Whole Foods grocery store will soon be opened with 260 apartment units built above it (Sarnoff, 2015). At the Ensemble/Houston Community College Station one stop south, more development is underway. The Mid Main mixed-use development will include 363 apartment units, retail, restaurants, and a parking garage (Kaplan, 2013). It is being built next to the MATCH art gallery and performance space as part of Midtown Houston's continued revitalization. 


\section{$3 \quad$ Methods}

\subsection{Data}

Harris County parcel-level land-use data from 2005, 2008, and 2014 were acquired from the H-GAC to evaluate land-use change in Houston (data for other years were not available). The 2005 land-use dataset is dated approximately one year after voters approved funding for the Red Line North, Green, and Purple lines, and after the Original Red Line began service. Given the relatively slow pace of development, this dataset is close enough to these events to serve as a baseline for land use at the time of LRT's introduction in Houston. The 2008 dataset characterizes land use three years later, just before construction began on the Red Line North, Green, and Purple lines. Land use from this period will provide an early glimpse at the effects of LRT operation in the case of the Original Red Line, and voter approval for LRT in the case of the other lines. The final land-use dataset comes from 2014, approximately 10 years after the Original Red Line opened, just after the opening of the Red Line North, and one year before the opening of the Green and Purple lines. This dataset will be used to detect longer-term landuse trends. The staggered LRT time frame provides an opportunity to study land-use change at varying stages of LRT implementation, from voter approval to construction, and finally, operation. Figure 1 presents a visual timeline depicting the full sequence of LRT implementation.

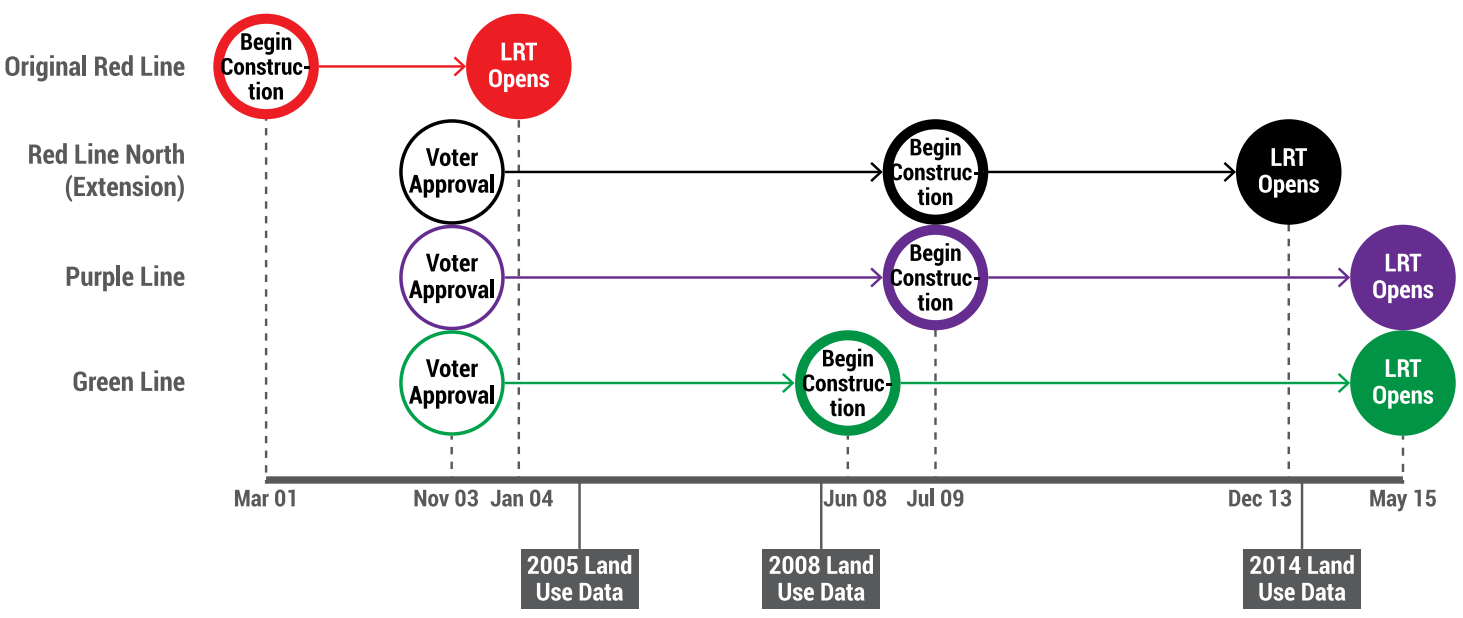

Figure 1: Timeline of Houston METRORail LRT events and H-GAC parcel data

\subsection{Analysis and control corridors}

The primary analysis corridor is the Original Red Line (i.e., the portion of the Red Line from the University of Houston-Downtown Station to Fannin South Station). The other existing LRT lines-the Red Line North, Green, and Purple lines - will also be examined, though LRT-related effects may not be observed given the recency of their opening. In this sense, they also serve as pseudo-control corridors.

In addition to these four existing LRT corridors, four control corridors were chosen to serve as a comparative baseline of land-use change and help account for external effects. The first two control corridors are the proposed Blue and Gold lines. Although the status of LRT expansion is currently in doubt in Houston, this uncertainty presents the opportunity to study land-use change along corridors marked as suitable for LRT, without having yet had any rail influence. Since the potential Blue Line crosses the Original Red and Purple lines, only the portion of it west of Montrose Boulevard was considered. 
The remaining two control corridors were identified by reviewing busy thoroughfares with frequent bus service within or near the I-610 Loop. The Long Point corridor (the portion of METRO Route 26 beginning at Long Point Rd. and Gessner Rd. and ending at E 20th St. and Studewood) and the Shepherd corridor (METRO Route 27 along Shepherd Dr.) were then selected based on their high levels of commercial activity and geographic separation from the other corridors.

Following selection of the analysis and control corridors, the corridors were buffered to select target parcels (Figure 2).

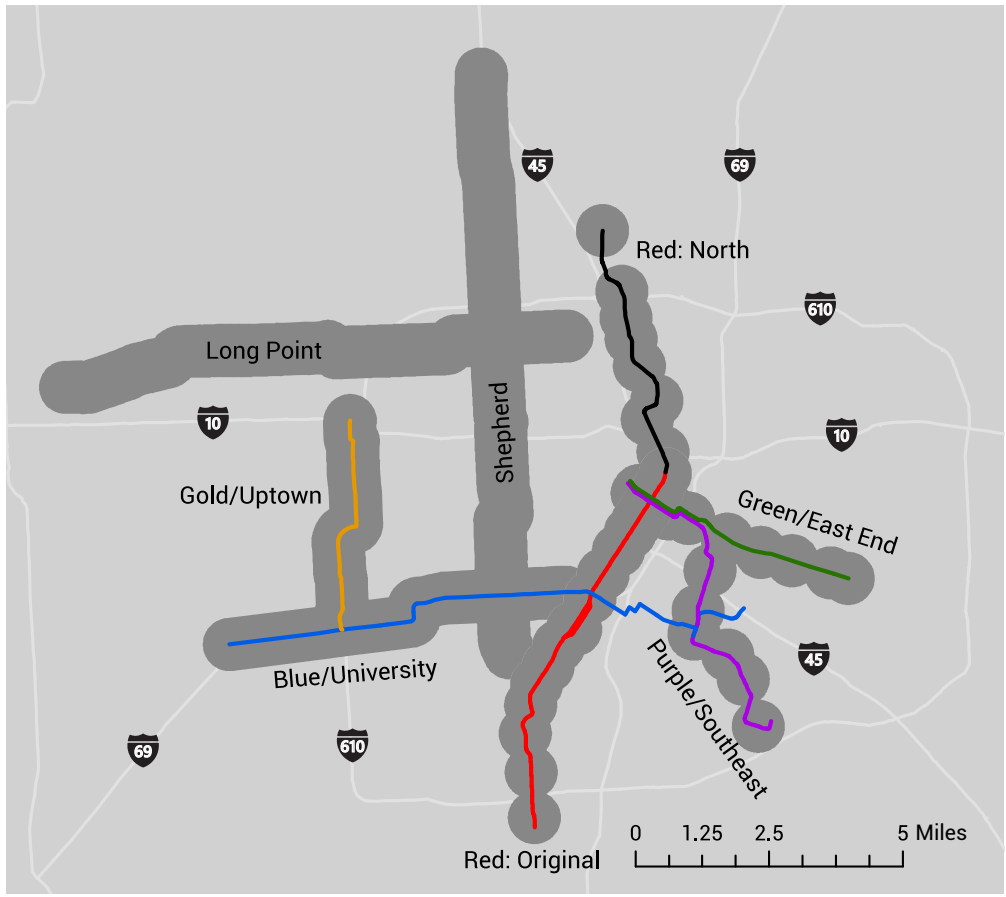

Figure 2: LRT and control corridors with 800-meter buffers.

An 800-meter (approximately half-mile) buffer distance was adopted as it is commonly recognized as the maximum acceptable walking distance to rail in the United States. The 800-meter standard is frequently used as the service radius for TODs and to develop ridership forecasts and zoning boundaries (Guerra, Cervero, \& Tischler, 2012). Existing rail lines were radially buffered around LRT stations, while control corridors were buffered along the entire linear extent. In cases where buffered corridors overlapped with the Original Red Line corridor, any overlapping parcels were removed (except in the case of the Original Red Line) so as not to confound results.

\subsection{Data processing and analysis}

Prior to analysis, the parcel datasets were processed and reclassified. 84 possible land-use categories were aggregated into seven land-use types: residential: single-family (primarily detached single-family households), residential: multifamily (dwellings of two to four families), residential: apartment (all larger residences of five families and greater), commercial, industrial, vacant, and other. The benefit of having highly disaggregated land-use data is that it allowed for the distinction between three residential land uses: single-family, multifamily, and apartment. Whereas previous studies have typically grouped all residential land uses together, we are able to better identify changes in residential density that might otherwise have been obscured. Areal proportions of each land-use type were then calculated within each 
corridor and within all of Harris County for the three analysis years (2005, 2008, and 2014).

Some studies have used regression-based approaches to analyze LRT and land-use change that are more statistically rigorous, but limited in other ways. Binary models can only measure the effect of LRT on whether or not a parcel changes land uses, but provide no insight into specific land-use types. Finer-grained multinomial models have better estimated the effect of rail proximity to land-use development, while controlling for built environment and socio-demographic factors, but still do not account for wider economic impacts. While more qualitative in nature, the comparative analysis performed in this study attempts to account for economic effects through the use of control corridors. This approach also has the benefit of being simple, replicable, and easy to understand for researchers or practitioners.

In addition to evaluating land-use change and development, this study was also interested in examining the effects of LRT on land-use mix, which is a principal element of TOD. Two commonly used measures were calculated to assess land-use mix changes, though both do so in very different ways. The first, the Entropy Index, considers how evenly mixed the proportion of land uses are in a given area. In contrast, the Multidimensional Balance Index compares how similar the land-use proportions for a target area are to a well-balanced reference area. For each measure, all three residential land-use types were aggregated because the walking and accessibility benefits of mixed land uses are theorized as coming from mixing residential land use with other land uses, rather than having a mix of residential densities. Therefore, our primary interest in measuring heterogeneity was to understand differences between these broader land-use categories. Aggregating residential land-use types had the effect of weighting residential land use equally with the other land-use types, as opposed to having it account for three of the seven categories.

The Entropy Index was calculated as follows:

$$
E N T=-\left[\sum_{j=1}^{k} P_{j} \ln \left(P_{j}\right)\right] / \ln (k)
$$

where $P_{j}$ represents the proportion of land-use type $j$, and $k$ is the total number of land-use types. The index is scaled from zero to one, with a value of one given in the case of perfectly mixed land uses (e.g. four land uses, each covering 25 percent of the region).

Unlike the Entropy Index, the Multidimensional Balance Index compares land-use mix to a wellbalanced reference geography rather than giving higher weight to equally proportioned areas. Its formulation is presented below:

$$
B A L=1-\sum_{j} t_{j}\left|r_{j}-t_{j}\right|
$$

where $t_{j}$ is the proportion of land-use category $j$ for the reference area, and $r_{j}$ represents the proportion of land-use category $\mathrm{j}$ for the study area. In this case, Harris County was selected as the base geography for comparison. While typically aggregating land use at the county level encompasses large proportions of rural land, Harris County is somewhat unique in that it is a primarily urban county sitting at the center of the nine-county Houston Metropolitan Statistical Area. Like the Entropy Index, the Multidimensional Balance Index ranges from zero to one with higher values indicating a more well-balanced land-use mix, or more specifically, land-use proportions more closely matching those of Harris County. Please refer to Song, Merlin, and Rodriquez (2013) for a more detailed discussion of these and other land-use mix measures. 


\section{$4 \quad$ Analysis}

\subsection{Initial conditions: 2005}

Figure 3 presents the initial land-use proportions for each corridor and the county. As of 2005, total residential land-use proportions were higher in every corridor than Harris County. The Red Line North and control corridors had the largest proportions of residential land use, at around 50 percent. In contrast, the Original Red, Green, and Purple LRT corridors had between 20-30 percent total residential land use. Single-family land use dominated the Long Point, Shepherd, and Red Line North corridors, as opposed to the Original Red Line with only 11 percent. Multifamily land use (residential dwellings of two to four families) was relatively low in every corridor, with the Blue and Green lines having the highest proportion at approximately five percent. For high-density apartment land use (dwellings of five families or more), the highest concentrations were found along the Gold and Blue corridors (21 percent and 17 percent) followed by the Original Red Line (8 percent). While the Original Red Line had the lowest level of total residential land use, a large proportion of that land was devoted to higher-density apartment parcels.

It is no surprise that every corridor had a large amount of commercial land, given that a high concentration of commercial development was a prerequisite for the selection of LRT and the control corridors. Commercial land-use proportions ranged from 20 to 49 percent, significantly higher than countywide levels (8 percent). The Original Red Line was on the lower end of this range ( 23 percent), but was the only corridor with more commercial land than residential land.

Vacant parcels were most predominant along the three new LRT corridors as well as the Shepherd control corridor. The Blue, Gold, and Long Point control corridors had the lowest levels of vacant land use, while nine percent of the Original Red corridor was devoted to vacant parcels, similar to county levels. The Green Line was the only corridor to have a significant proportion of industrial land use (8 percent). Otherwise, industrial land proportions ranged between 0 and 2 percent. Finally, the Original Red and Purple LRT corridors had by far the largest amount of land designated as "other," which was predominantly university- and government-owned lands. In the case of the Original Red corridor, Rice University, Hermann Park, and the Texas Medical Center made up the majority of other land-use parcels. Along the Purple corridor, the University of Houston, Texas Southern University, and MacGregor Park were the primary contributors. 

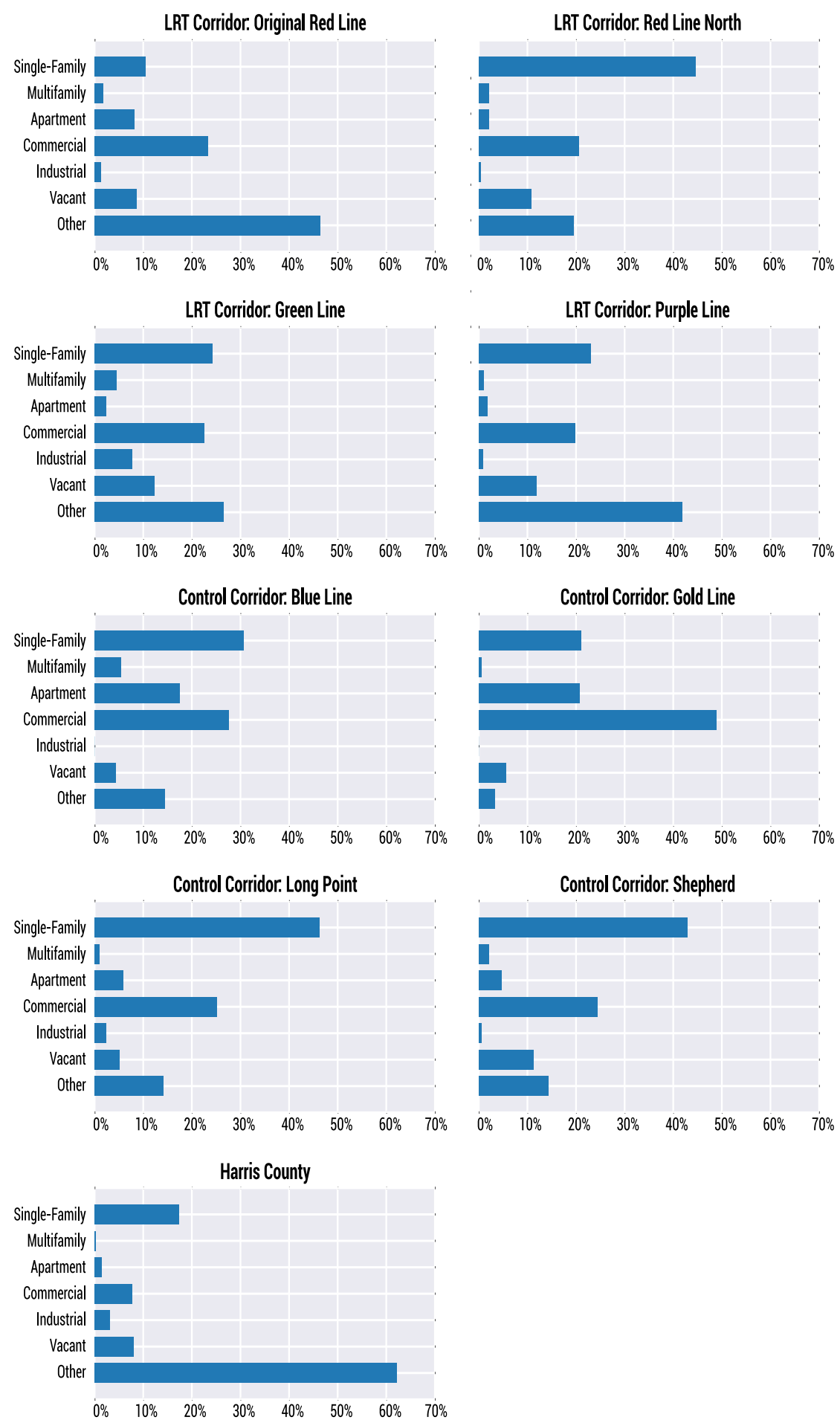

Figure 3: 2005 land-use proportions for LRT corridors, control corridors, and Harris County 


\subsection{Land-use change: $2005-2014$}

Figure 4 presents the results of the land-use change analysis by corridor. From 2005 to 2014, the Shepherd control corridor had the largest absolute gains in single-family housing. During the first study period (2005 to 2008), the corridor had a 2.1 percentage point increase in single-family parcel area, followed by a 0.7 percentage point increase in the second study period (2008 to 2014). The other corridors followed a similar pattern, to a lesser extent, with larger gains during the first period ( 0.5 to 1.1 percentage points) preceding more modest gains in the second period ( 0.1 to 0.5 percentage points). These trends roughly mirrored countywide trends, though Harris County saw a slight decline in singlefamily housing from 2008 to 2014 . Changes in multifamily residential land use were mostly negligible during the entire study period, with very slight declines in every corridor except for the Purple Line. Small increases in high-density apartment land use were evident along the Original Red, Green, and Purple LRT lines, as well as the Long Point control corridor, while the Blue Line and Shepherd control corridors experienced small declines. The Gold Line demonstrated the most dramatic change in the proportion of high-density residential land use. Following a 0.8 percentage point increase from 2005 to 2008, apartment land use fell by 2.9 percentage points between 2008 and 2014. As a result, the Gold corridor had a net decline in total residential land use over the course of the study period, in sharp contrast to the other corridors and the rest of Harris County.

Following a small decline during the first study period, the Original Red Line corridor had by far the largest increase in commercial land use during the second study period, and the greatest gains overall. The Green Line corridor was the only other corridor to increase its proportion of commercial land by over one percentage point, though unlike the Original Red Line corridor, these gains primarily occurred during the first study period. Otherwise, changes in commercial land use were relatively modest and similar to Harris County trends.

Both the analysis and control corridors tended to diverge from the rest of the county when it came to the proportion of vacant parcels. While vacant land increased in Harris County by approximately one percentage point, proportions of vacant land in the corridors tended to stagnate or decrease, particularly in the case of the Green and Purple line corridors (declines of 2.3 and 1.6 percentage points, respectively). As was the case for residential land use, the lone exception to this trend was the Gold Line corridor, which had a substantial 3.2 percentage point increase in vacant land during the second study period. Similar to vacant land use, other land uses declined in nearly every corridor during both study periods, suggesting that many of the gains in residential and commercial land use came at the expense of vacant and other parcels. Industrial land remained relatively unchanged from 2005 to 2014 with the largest gains seen along the Purple Line corridor. 

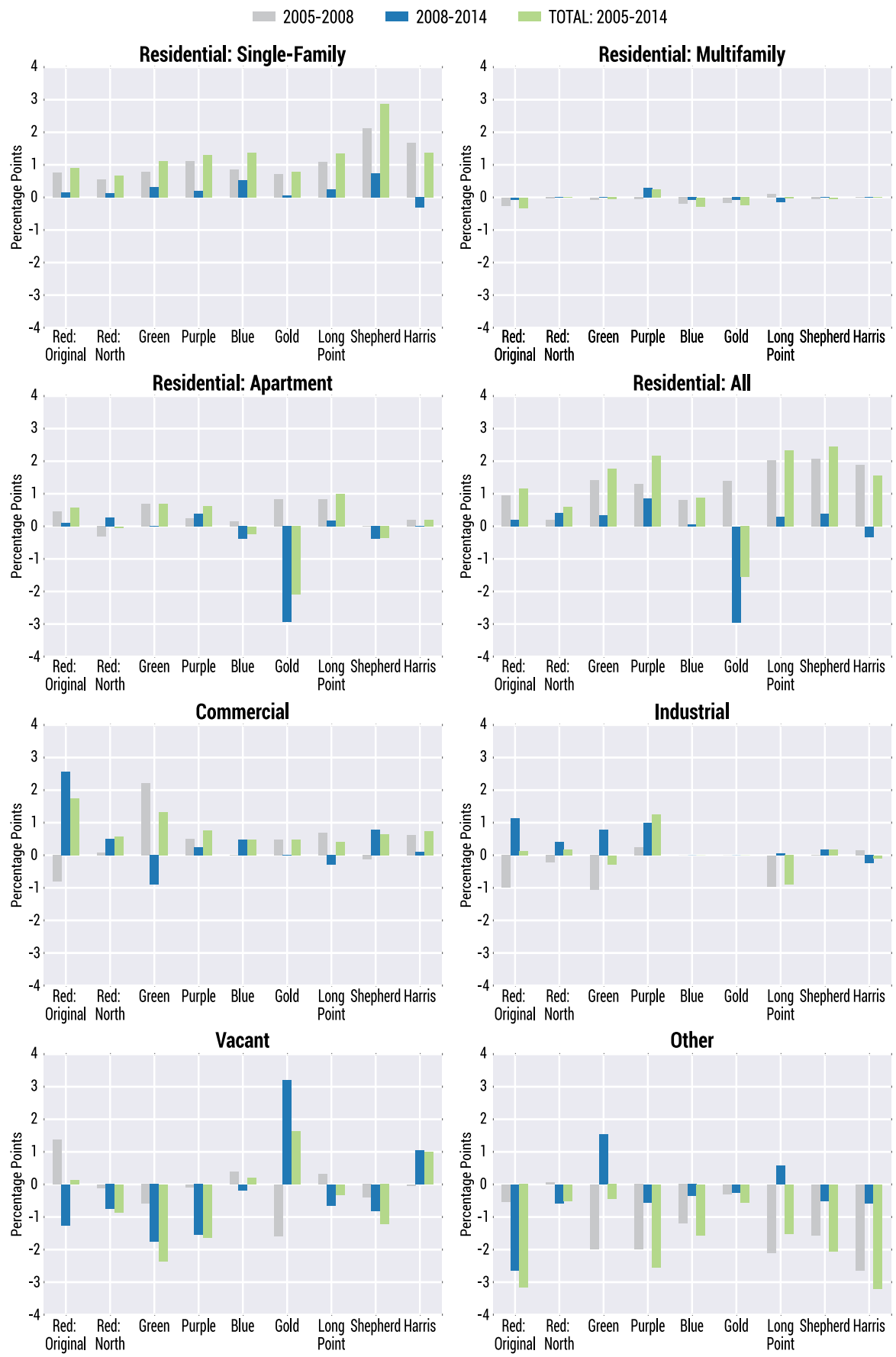

Figure 4: Land-use change: 2005-2008, 2008-2014, 2005-2014 


\subsection{Land-use mix}

Results of the land-use mix analysis revealed greater land-use heterogeneity along the LRT corridors compared to the control corridors (Figure 5). According to the Entropy Index, the Green Line corridor was the most mixed (i.e., more evenly balanced) and every LRT corridor was ranked as more mixed than the control corridors. The Original Red Line and Gold Line corridors saw the largest increase in landuse mix during the second study period. LRT corridors also scored higher than the control corridors by the Multidimensional Balance Index, where higher values are associated with land-use mix proportions more closely matching Harris County. In this case, the Original Red and Purple lines ranked highest (mainly driven by their higher levels of other land use), while the Gold Line again ranked as the poorest mixed given its predominance of residential and commercial land uses.
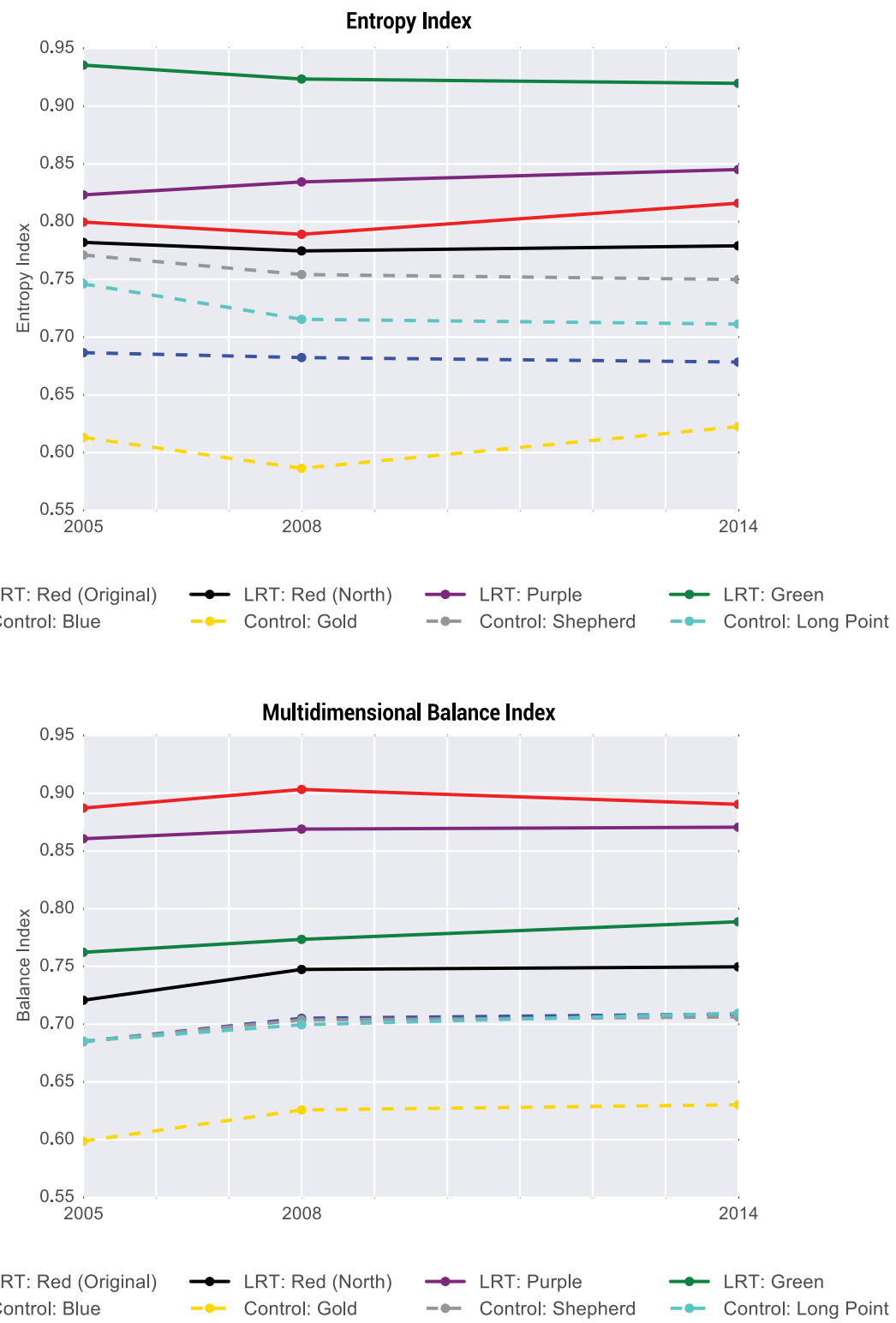

Figure 5: Land-use mix indices for 2005, 2008, and 2014 


\section{Discussion}

The primary question of interest was whether or not LRT in Houston has encouraged development, and TOD in particular. To begin to answer this question, it is useful to consider four indicators: change in commercial land, change in residential land (especially high-density apartment land use), change in vacant parcels, and land-use mix.

By the first measure, change in commercial land, a large increase in commercial development within the Original Red Line corridor provided evidence that LRT had a positive impact on development. However, it should be noted that commercial property declined within the Original Red corridor from 2005 to 2008, soon after LRT began operation. This decline was in contrast to the other corridors and the rest of the county, suggesting that broader economic effects were not to blame. It could be the case that the initial introduction of LRT drove up nearby property values, depressing commercial development. The Green Line corridor also increased its proportion of commercial land, but these changes primarily occurred during the first study period before construction on the line had even begun. The subsequent decline in the second period therefore makes it difficult to attribute commercial development to LRT.

In terms of residential land use, increased development was seen across the county and in every corridor except the Gold Line. The largest absolute increases occurred along the Shepherd and Long Point control corridors as well as the Green and Purple LRT corridors, but on a percentage basis the Purple and Original Red corridors saw the greatest gains. When considering just high-density residential development, only the Long Point, Original Red, Green, and Purple corridors had positive gains over the entire study period. Though the Original Red corridor saw increased residential development, the magnitude of this growth was not markedly different from that seen in the other corridors.

Looking at changes in the proportion of vacant land revealed that the largest declines tended to occur along the recently opened LRT corridors (Red Line North, Green, and Purple lines), even as vacant land proportions increased in the county. These declines primarily occurred during the second study period, the beginning of which coincided closely with the beginning of construction on those lines in 2008 and 2009. It is possible that the imminent prospect of LRT spurred this reduction in vacant land. In contrast, the Original Red Line corridor exhibited very little change in its proportion of vacant land from 2005 to 2014. There are three plausible explanations for this finding: 1) LRT had little effect on demand for land in the corridor; 2) LRT increased demand along the corridor, but effects occurred in the years leading up to the opening of the line before data were available, after which demand re-stabilized; and 3) increased demand was balanced out by an attendant rise in property values.

Lastly, land-use mix was compared using two measures of heterogeneity. By either measure, every LRT corridor ranked as more mixed than their control counterparts. There was no indication that landuse mix markedly changed as a result of LRT, but it appears that a strong mix of land uses is at least a prerequisite for LRT development.

Overall, it appeared that the Original Red Line attracted development several years after its opening, beyond what was seen in the other corridors or county. Land-use development is often a slow process so it was not surprising that minimal effects were found for the other more recently opened LRT corridors. Corroborating findings from a recent case study of the Original Red Line (United States Government Accountability Office, 2014), the positive development effect was primarily seen for commercial land as opposed to residential land, though this may change in the coming years—several large residential and mixed-use projects currently under development in the Midtown area and elsewhere within the corridor were not captured in this analysis.

As always, the problem of self-selection makes it challenging to make declarations of causality. LRT 
may be a driver of land-use change, but it is also true that LRT tends to be situated in locations already conducive to land-use change. Control corridors helped isolate the influence of LRT by identifying broader area-wide trends, but also had limitations in terms of their explanatory power. Because it is not possible to find exact surrogates for LRT corridors, the control corridors differed in terms of land-use composition and socioeconomic characteristics. There is a reason, after all, that the LRT corridors were selected for rail in the first place and the control corridors were not. In particular, no other area of the city can match the density and attractions found along the Original Red Line corridor, which runs directly through downtown and the CBD. How much of the growth in this area is attributable to LRT and how much is simply the result of downtown Houston's revitalization is difficult to determine. For this reason, the recently opened Red Line North, Green, and Purple lines will provide an excellent opportunity for further research as they mature.

This study also aimed to evaluate the benefit of stratifying residential land uses by density, which helped uncover trends that would have otherwise been obscured. For instance, the Shepherd and Long Point control corridors were nearly identical in terms of total residential land-use proportions and change, but highly divergent when considering changes in residential density. Similarly, the reduction in residential land along the Gold Line corridor is even more striking upon considering the fact that it was driven almost entirely by a loss in high-density apartment land.

\section{Conclusion}

LRT is beginning to take hold in what has traditionally been an auto-oriented city with a unique planning and land-use environment. Results of the land-use change analysis revealed increased development along LRT corridors, though study limitations make it difficult to directly attribute these changes to rail. Continued study of the three more recent LRT corridors will be beneficial to evaluate whether they will follow a similar development trajectory to that of the Original Red Line. Being located outside of the CBD, these newer rail corridors are also more comparable to other areas of the city and can provide stronger evidence for the association between LRT and land use in Houston.

This study differed from others in its distinction between residential land-use types. Disaggregate residential land-use types aided in identifying areas of densification-an important component of TOD planning. In the case of one corridor (Shepherd), the proportion of high-density residential land use decreased despite a growth in overall residential development—a fact that would have been obscured had all residential land uses been combined. Based on these insights, it is strongly recommended that planners and researchers make a distinction between high- and low-density residential parcels, where suitably disaggregate land-use data are available. It is not necessarily the case that an increase in residential land use will be transit-supportive.

\section{Acknowledgements}

The research reported in this publication was motivated by the National Institute of Diabetes and Digestive and Kidney Diseases of the National Institutes of Health under Award Number R01DK101593. The content is solely the responsibility of the authors and does not necessarily represent the official views of the National Institutes of Health. The authors would like to acknowledge the valuable comments of two anonymous reviewers and the editor on an earlier version of this paper. The first author would like to dedicate her part of the research efforts to the memory of her dear father, Erdinc Sener, who passed away in October 2015. 


\section{References}

Begley, D. (2016, May 24). Federal funding pulled for light rail line construction along Richmond Avenue. Houston Chronicle. Retrieved from http://www.chron.com/news/houston-texas/houston/ article/University-Line-federal-funding-pledge-pulled-7846885.php

Cervero, R. (1984). Journal report: Light rail transit and urban development. Journal of the American Planning Association, 50(2), 133-147.

Cervero, R., \& Guerra, E. (2011). Urban densities and transit: A multi-dimensional perspective (Publication No. UCB-ITS-VWP-2011-6). Berkeley, CA: Institute of Transportation Studies, University of California, Berkeley.

Cervero, R., \& Zupan, J. (1996). Commuter and light rail transit corridors: The land use connection (TCRP Project H-1). Washington, DC: Transit Cooperative Research Program.

City of Houston. (n.d.). Livable centers studies. Retrieved from http://www.houstontx.gov/planning/ transportation/LivableCenter.html

City of Houston. (2011). Residential Buffering Ordinance. Retrieved from http://www.houstontx.gov/ planning/DevelopRegs/hidensity/adopted_resident_buffer_ordnce.pdf

Cohen-Blankshtain, G., \& Feitelson, E. (2011). Light rail routing: Do goals matter? Transportation, 38(2), 343-361.

Dueker, K. J., \& Bianco, M. J. (1999). Light-rail-transit impacts in Portland: The first ten years. Transportation Research Record, 1685, 171-180.

Fogarty, N., \& Austin, M. (2011). Rails to real estate: Development patterns along three new transit lines. Berkeley, CA: Center for Transit-Oriented Development.

Goetz, E. G., Ko, K., Hagar, A., Hoang, T., \& Matson, J. (2010). The Hiawatha Line: Impacts on land use and residential housing value (Publication No. CTS 10-09). Minneapolis, MN: Center for Transportation Studies, University of Minnesota.

Guerra, E., Cervero, R., \& Tischler, D. (2012). Half-mile circle. Transportation Research Record, 2276, 101-109.

Handy, S. (2005). Smart growth and the transportation-land use connection: What does the research tell us? International Regional Science Review, 28(2), 146-167.

Hassell, W., Lewis, C. A., \& Auzenne, J. (2014). The effect of the city of Houston Transit Corridor Ordinance on development along METRO's light rail corridors (Publication No. SWUTC/14/600451-00047-1). College Station, TX: Texas A\&M Transportation Institute.

Higgins, C., Ferguson, M., \& Kanaroglou, P. (2014). Light rail and land-use change: Rail transit's role in reshaping and revitalizing cities. Journal of Public Transportation, 17(2), 93-112.

Houston Chronicle. (2013, March 22). Houston rail, reborn: Bus rapid transit in uptown deserves funding to create a right-of-way for buses. Houston Chronicle. Retrieved from http://www.chron. com/opinion/editorials/article/Houston-rail-reborn-4377902.php

Hurst, N. B. (2011). How does light rail transit affect urban land use? (Honors project). St. Paul, MN: Macalester College.

Hurst, N. B., \& West, S. E. (2014). Public transit and urban redevelopment: The effect of light rail transit on land use in Minneapolis, Minnesota. Regional Science and Urban Economics, 46, 57-72.

Kaplan, D. (2013, September 28). Mid main project will ride with the millenials. Houston Chronicle. Houston, TX. Retrieved from http://www.houstonchronicle.com/business/article/Mid-Main-project-will-ride-with-the-millennials-4851864.php

Knowles, R. D., \& Ferbrache, F. (2016). Evaluation of wider economic impacts of light rail investment on cities. Journal of Transport Geography, 54, 430-439. 
Lewyn, M. (2005). How overregulation creates sprawl (Even in a city without zoning). Wayne Law Review, 50(1171).

Margerum, R. D., Brody, S., Parker, R., \& McEwen, G. (2013). Metropolitan smart-growth centers: An assessment of incentive policies in four regions. Journal of Transport and Land Use, 6(2), 21-32.

Metropolitan Transit Authority of Harris County Texas. (2016). Ridership reports. Retrieved from http:// www.ridemetro.org/Pages/RidershipReport.aspx

Mulvaney, E. (2015, May 28). Midtown project breaks ground with high hopes. Houston Chronicle. Houston, TX. Retrieved from http://www.houstonchronicle.com/business/real-estate/article/Midtown-project-breaks-ground-with-high-hopes-6292968.php

Ozdil, T. R., Taylor, P. D., Li, J., Mattingly, S., \& Bell, B. (University of Texas at Arlington). (2011). Transit-oriented development report. Arlington, TX: North Central Texas Council of Governments.

Pacheco-Raguz, J. F. (2010). Assessing the impacts of light rail transit on urban land in Manila. Journal of Transport and Land Use, 3(1), 113-138.

Porter, D. (1998). Transit-focused development and light rail systems: The lite connection. Transportation Research Record, 1623, 165-169.

Qian, Z. (2010). Without zoning: Urban development and land-use controls in Houston. Cities, 27(1), $31-41$.

Ratner, K. A., \& Goetz, A. R. (2013). The reshaping of land use and urban form in Denver through transit-oriented development. Cities, 30(1), 31-46.

Sarnoff, N. (2015, May 8). Midtown project to combine Whole Foods, luxury apartments. Houston Chronicle. Houston, TX. Retrieved from http://www.houstonchronicle.com/business/real-estate/ article/Midtown-project-to-combine-Whole-Foods-luxury-6250297.php

Shen, Q. (2013). Under what conditions can rail transit induce higher density? Evidence from four metropolitan areas in the United States, 1990-2010 (Doctoral dissertation). Ann Arbor, MI: University of Michigan.

Song, Y., Merlin, L., \& Rodriguez, D. (2013). Comparing measures of urban land-use mix. Computers, Environment and Urban Systems, 42, 1-13.

United States Government Accountability Office. (2014). Multiple Factors Influence Extent of TransitOriented Development (Publication No. GAO-15-70). Washington, DC: United States Government Accountability Office. 